\title{
Receptor Activator of NFKB Ligand (RANKL) Stimulates the Differentiation of Osteoclast Progenitors of the Macrophage Lineage into Osteoclasts in the Presence of Macrophage Colony-Stimulating Factor (MCSF)
}

\author{
Prisca Pakan ${ }^{1}$, Nicholas Andronicos ${ }^{2}$ \\ ${ }^{1}$ Faculty of Medicine, Universitas Nusa Cendana, Kupang, Indonesia \\ ${ }^{2}$ Molecular Genetics and Developmental Biology Department, University of New England, Australia. \\ priscapakan@yahoo.com, ${ }^{2}$ nandroni@une.edu.au
}

\begin{abstract}
Cytokine Macrophage Colony Stimulating Factor (MCSF) and Receptor Activator of NFKB Ligand (RANKL) induces the differentiation of macrophages into osteoclast cell using RAW264.7 line cell in vitro, marked by the alterations in gene expression of the progenitor cells that typify osteoclast cells. In order to determine this, the experiment was conducted using hematopoietic precursor cells to examine the cellular differentiation into osteoclast under the control of RANKL. Subsequently, microarrays were used to accurately analyse the expression of the genes of interest by exhibiting the gene expressions changes and expected regulations of osteoclasts marker genes. The upregulation of TRAP mRNA expression indicated the characteristic of osteoclast cells in the progenitor cells, which generated from the analysis of RANKL.
\end{abstract}

\section{A. INTRODUCTION}

Macrophages change their physiology in response to environmental changes that may give incremental changes in the cell population. The established pathway of macrophages activation is through the pathway of Interferon-¥-dependent activation by $\mathrm{T}$ helper 1 . Macrophages function as human's immune system that eradicates infectious agents, cancer cells and maintaining tissue homeostasis (Gordon, 2003). Macrophage colony stimulating factor (MSCF) is one of the primary cytokine in osteoclast genesis for the proliferation and differentiation of osteoclast precursors. This is then differentiated into TRAP, which indicated positive osteoclast. Osteoclasts are believed to belong to a macrophage lineage (Takeshita, Kaji, Kudo, 2000).

Osteoclast is defined as cells that developed from macrophages hematopoietic lineage; conforms to the bone matrix and degrade acid as well as lytic enzymes into extracellular compartment (Boyle, Simonet, Lacey, 2003).

Furthermore, osteoclast is an important factor in bone remodelling in order to regulate and function normally throughout the human life. Disproportion of bone remodelling may cause several skeletal muscle diseases such as osteoporosis, periodontal disease, rheumatoid arthritis, myeloma and metastatic cancers. The knowledge of the stimulation and activation of osteoclast cell are required to unfold the process in bone metabolism and remodeling in order to formulate therapeutic agents for these diseases (Cappeleni et al. 2002). In addition, Boyle et al. (2003) stated that physiological and pathophysiological effects of TNF related cytokines, such as RANKL on bone mass and how it initiates osteoclast genesis are also important to appreciate.

RANKL and polypeptide growth factor CSF-1 (MCSF) are required to induce the expression of osteoclast; including Tartrate-resistant Acid Phosphate (TRAP), Cathepsin K (CATK), Calcitonin receptor. When activated by RANKL, the progenitor cells are subject to make structural alterations in order to reabsorb bone. Lytic enzymes TRAP and pro CATK are then exported into the reabsorption region (Howship Lacunae). This process deteriorates the underlying bone and the degraded products are subsequently processed within the osteoclast and discharged into the circulation system (Boyle et al, 2003).

In the present study, we verified the theories of cell differentiation of macrophages into osteoclasts by inducing RANKL and MCSF and subsequently analyze the gene expression patterns during in vitro differentiation of RAW264.7 cell line. The results will determine whether RANKL and MSCF as primary cytokines have the ability to upregulate the genes expression of the encoding receptor of osteoclast such as TRAP.

\section{B. METHOD}

Harvesting the RAW264.7 cells. In order to culture the mouse myeloid/macrophage tumor cell line, RAW264.7, a $5 \mathrm{~mL}$ of the culture medium in the dish of RAW264.7 cells was gently squirted over the entire inside bottom of the dish to dislodge the cells. This procedure was repeated several times until the hazy layer of the cells is dislodged and suspended in the medium. The cell suspension was span at 1000 $\mathrm{rpm}$ for 5 minutes at room temperature. The supernatant was discarded and another $10 \mathrm{ml}$ of 
Complete Medium was added to the cell pellet to suspend the cell again.

Refer to Table 1, for the amount of medium, bone marrow suspension and RANKL to be used.

Tabel 1. In vitro differentiation of RAW 264.7 cells

\begin{tabular}{|c|c|c|c|}
\hline $\begin{array}{c}\text { Tube } \\
\text { Labe } \\
1\end{array}$ & $\begin{array}{c}\text { Complet } \\
\mathrm{e} \\
\text { Medium }\end{array}$ & $\begin{array}{c}\text { Bone } \\
\text { Marrow } \\
\text { Cell } \\
\text { Suspensio } \\
\mathrm{n} \\
\end{array}$ & $\begin{array}{c}\text { RANKL } 20 \\
\mu \mathrm{g} / \mathrm{ml}\end{array}$ \\
\hline $\mathrm{U}$ & $3 \mathrm{ml}$ & $2 \mathrm{ml}$ & - \\
\hline $\mathrm{R}$ & $3 \mathrm{ml}$ & $2 \mathrm{ml}$ & $\begin{array}{cc}20 & g / m \\
1\end{array}$ \\
\hline
\end{tabular}

Cell differentiation was performed by incubation in Complete Medium with or without RANKL. Culture medium was replaced on day 3 and day 6 of treatment. In addition, another cell cultures was prepared for differentiation by firstly incubating cell suspension in the tissue culture incubator $\left(95 \%\right.$ air $\left./ 5 \% \mathrm{CO}_{2}\right)$; these cells were harvested on the next day for RNA preparation.

Meanwhile, the remaining volume in tubes $\mathrm{U}$ and $\mathrm{R}$ was used to set up separate cultures for cell staining on the next two days.

Cell fixation, staining and phenotypic analysis. Both the cell cultures prepared were used. Cell fixation was achieved by using Cell Fixative and MUST BE performed in a fume hood by gently adding $0.5 \mathrm{~mL}$ of Cell Fixative (Note: hazardous material) per well and leave in the fume hood for 30 seconds ONLY and proceed with preparation of the Diazotized TRAP Stain. Light microscope was used to examine the phenotype of the stained cells.

Cell lysis and RNA extraction using Aurum ${ }^{\mathrm{TM}}$ Total RNA Mini Kit, the procedure was conducted according to the manufacturer's protocol.

Digestion of genomic DNA. The purified RNA acquired was treated with RNase-free DNase I to degrade any genomic DNA remaining in the sample.

First-strand cDNA synthesis. In order to reverse transcribe the mRNA in the samples to obtain firststrand cDNA using an INVITROGEN SuperScript III First-Strand Synthesis SuperMix-for-RT-PCR kit. This included RNase $\mathrm{H}$ digestion of the RNA strand in the cDNA/RNA duplex.

$R T-P C R$ analysis. This assayed the expression level of three genes:
a. Glyceraldehyde 3-phosphate
dehydrogenase (GAPDH)
b. Tartrate-resistant acid phosphatase (TRAP)
c. c-Fms

Agarose gel electrophoresis. The agarose gel electrophoresis of PCR products used agarose gel electrophoresis to separate the amplimers obtained from the RT-PCR reactions in order to detect the presence of three mRNAs.

\section{RESULTS}

1. Cell Fixation, Staining and Phenotypic Analysis

The cell size and population analysis in the untreated cells with RANKL (U1 and U7) showed relatively below the range of RANKL induced cell for 7 days (R7), as summarised in Table 1. Although R1 cell was treated with RANKL, the treatment was only for 1 day and therefore, the result is similar to the RANKL untreated cells. TRAP staining positive cells were apparent in the 7 days of RANKL treatment (R7). The multinucleated cells are exhibited by R7, as expected due to the cell sizes of $\mathrm{R} 7$ which are larger and hence indicated that it has more nuclei (Fig 1).

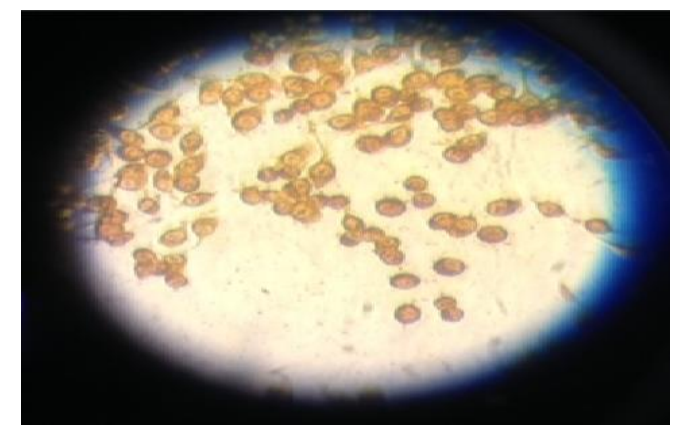

Figure 1. The light microscopic images which show the cell population and cell morphological difference of which was not induced by RANKL for 7 days (U7)

Table 2. The phenotypic changes of harvested RAW264.7 cells untreated with RANKL for 1 day (U1) and 7 days (U7) and treated with $20 \mu \mathrm{l}$ of RANKL for 1 day (RI) and for 7 days (R7).

\begin{tabular}{|c|c|c|c|c|}
\hline Cell Size & $\begin{array}{c}\text { Small } \\
\text { cell } \\
\text { size }\end{array}$ & $\begin{array}{c}\text { Small } \\
\text { cell } \\
\text { size }\end{array}$ & $\begin{array}{c}\text { Small } \\
\text { cell size }\end{array}$ & $\begin{array}{c}\text { Large } \\
\text { cell size }\end{array}$ \\
\hline $\begin{array}{c}\text { Cell } \\
\text { (s) }\end{array}$ & Low & Low & Low & High \\
\hline $\begin{array}{c}\text { TRAP } \\
\text { Staining }\end{array}$ & $\begin{array}{c}\text { Negat } \\
\text { ive }\end{array}$ & $\begin{array}{c}\text { Negati } \\
\text { ve }\end{array}$ & $\begin{array}{c}\text { Negativ } \\
\text { e }\end{array}$ & $\begin{array}{c}\text { Positive } \\
\text { (Dark } \\
\text { Pink } \\
\text { colour) }\end{array}$ \\
\hline $\begin{array}{c}\text { Multinucl } \\
\text { eated } \\
\text { cells }\end{array}$ & No & No & No & Yes \\
\hline
\end{tabular}




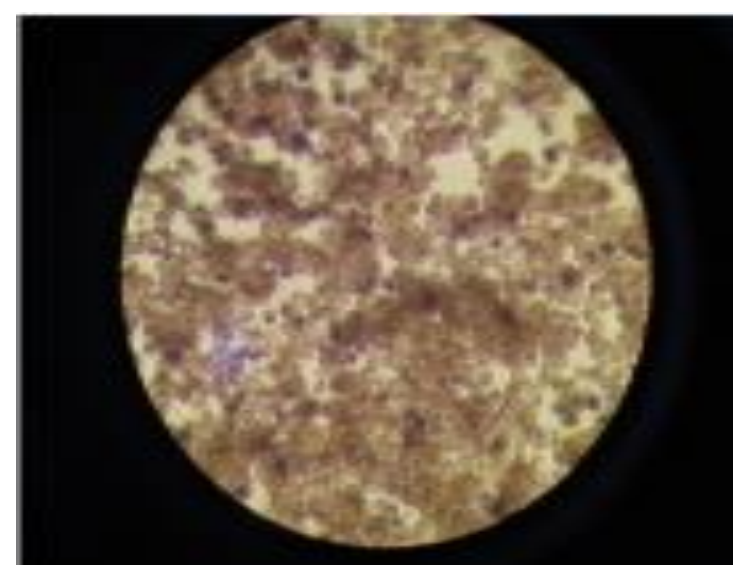

Figure 2. Culture cell induced by $20 \mu \mathrm{l}$ of RANKL for 7 days (R7). This also represented the TRAP staining activity and the multinucleated cell.

12345678910111213

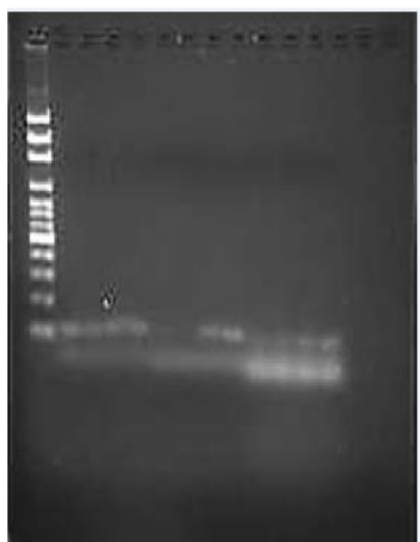

Fig 3. The agarose electrophoresis of the c-DNA product

2. Using Gene Expression Changes to Monitor Macrophage and Osteoclast Differentiation.

After extracting RNA, the next step was RTPCR procedure in order to see the gene expression of macrophages and osteoclast cell differentiation under the influence of RANKL. The RT-PCR assay were used to analysed the expression of Glyceraldehyde 3phosphate dehydrogenase (GAPDH), Tartrateresistant acid phosphate (TRAP) and c-FMS, which were prepared into 12 tubes and loaded in certain order (Table 2.)

The result of agarose gel electrophoresis of the PCR products shown in Fig 3 showed a relatively precise expected amplifications from the genes. It can be clearly seen that in the lanes of control (GAPDH) were evenly and constantly expressed while TRAP and c-FMS lanes were also expressed, but in different intensity. This means that RANKL were able to induce the expression of TRAP mRNA.

Table 3. The order which the tubes were loaded into the PCR and subsequently amplified into the Agarose Gel Electrophoresis.

\begin{tabular}{|c|c|c|}
\hline PCR Tube & $\begin{array}{c}19 \mu 1 \text { of } \\
\text { Primers } \\
\text { Master Mix }\end{array}$ & $\begin{array}{c}1 \mu \text { of } \\
\text { cDNA } \\
\text { sample }\end{array}$ \\
\hline 1 & - & - \\
(Standard) & GAPDH & U1 \\
\hline 2 & GAPDH & R1 \\
\hline 3 & GAPDH & U7 \\
\hline 4 & GAPDH & R7 \\
\hline 5 & TRAP & U1 \\
\hline 6 & TRAP & R1 \\
\hline 7 & TRAP & U7 \\
\hline 8 & TRAP & R7 \\
\hline 9 & C-FMS & U1 \\
\hline 10 & C-FMS & R1 \\
\hline 11 & C-FMS & U7 \\
\hline 12 & C-FMS & R7 \\
\hline 13 & \multicolumn{2}{|l}{} \\
\hline
\end{tabular}

\section{DISCUSSION}

MCSF (Macrophage Colony Stimulating Factor) is expressed constitutively in the bone microenvironment in response to the incremental change of PTH and inflammatory molecules such TNF or RANKL (Yavropoulou, Yovos, 2008). In this study, osteoclast cells were differentiated in vitro using murine stem cell bone marrow. Due to the presence of MCSF, macrophages were differentiated and RANKL activated TRAP which is the marker for osteoclast. Consequently, the mononucleus progenitor cells altered the motif of their gene expression. These occurred by cells migrating and fusing to one another and thus formed cells with multiple nucleai. As cells continue fusing to each other, the cells get larger in size and become multinucleated (refer to Table 1). At day 7 of incubation (Fig 2), it has reached the sufficient time for the RANKL concentration, the huge circular shaped cells continue to fused into large cytoplasmic masses, therefore the cells density continue to increased (Gardner, 2006).

GAPDH

Glyceraldehyde 3-phosphate dehydrogenase (GAPDH) is used as comparison to gene expressions data due to its constitutively expressed gene or as 
referred to as a "housekeeping" gene (Barber, Harman, Coleman, Clark, 2005). Barber et al (2005) asserted that although several other "housekeeping" genes might be expressed differently between body tissues, it is proven that GAPDH can be used as internal control for the normalisation in gene expression data, particularly during apoptosis. As a housekeeping genes, constant level of expression in the tissue are supposedly preserved (Eisenberg and Lovanon, 2013). This theory is consistant with the result in both Fig 3 which in the lane 2, 3, 4, and 5 the stains were amplified in a stabilized manner. Therefore, these amplifications are not related to whether osteoclasts are associated with this effect or not, but GAPDH are used as internal control.

TRAP

The theory of TRAP is that it is a cytochemical marker of osteoclasts and its biochemical concentration in serum can be used to analyze osteoclast function and levels of bone resorption because TRAP is secreted in large amount by osteoclasts (Ballanti et al. 1997). Based on the ground of this, lane 6, 7, 8 and 9 (Fig 3) there were gene expressions on these, however, they are expressed in a different degree. Lane 6 and 7 (Fig 3) were untreated RANKL cells day 1 and day 7 (U1 and U7), therefore, the gene expression of TRAP were not as much as in lane 8 and 9 (R1 and R7) which were treated with RANKL. The overexpression in lane 8 and 9 are most likely due to the existence of RANKL. $C$-FMS

$\mathrm{C}$-FMS is a precursor for the mature and late stage of osteoclastogenesis (Hofstetter, Wetterwald, Cecchini, Felix, Fleish, Mueller, 1992). As shown in Fig 3, although lane 10 until 13 were expressed, it can be clearly seen that in lane 13 which is RANKL induced for 7 days exhibited more vivid stain, which indicated a greater expression.

\section{E. CONCLUSSION}

Based on our experiments, the results has indicated that RANKL were not able to activate the expression of TRAP mRNA. The results exhibited otherwise (Fig 2), as TRAP assay was positive particularly for culture cell of day 7 with RANKL treatment, it exhibited an strong expression which emphasizes the cellular differentiation into osteoclasts.

\section{REFERENCES}

Ballanti, P., Minisola, S., Pacitti, M. T., Scarnecchia, L., Rosso, R., Mazzuoli, G. F., \& Bonucci, E. (1997). Tartrate-resistant acid phosphate activity as osteoclastic marker: Sensitivity of cytochemical assessment and serum assay in comparison with standardized osteoclast histomorphometry. Osteoporosis International: A Journal Established as Result of Cooperation between the European Foundation for Osteoporosis and the National Osteoporosis Foundation of the USA, 7(1), 39-43. doi:10.1007/BF01623458

Barber, R. D., Harmer, D. W., Coleman, R. A., \& Clark, B. J. (2005). GAPDH as a housekeeping gene: Analysis of GAPDH mRNA expression in a panel of 72 human tissues. Physiological Genomics, 21(3), 389395.

doi:10.1152/physiolgenomics.00025.2005

Boyle, W. J., Simonet, W. S., \& Lacey, D. L. (2003). Osteoclast differentiation and activation. Nature, 423(6937), 337-342.

Cappellen, D., Luong-Nguyen, N. H., Bongiovanni, S., Grenet, O., Wanke, C., \& Šuša, M. (2002). Transcriptional program of mouse osteoclast differentiation governed by the macrophage colony-stimulating factor and the ligand for the receptor activator of $N F \kappa B$. Journal of Biological Chemistry, 277(24), 21971-21982.

Eisenberg, E., \& Levanon, E. Y. (2013). Human housekeeping genes, revisited. Trends in Genetics : TIG, 29(10), 569.

Gordon, S. (2003). Alternative activation of macrophages. Nature reviews immunology, 3(1), 2335 .

Hofstetter, W., Wetterwald, A., Cecchini, M. C., Felix, R., Fleisch, H., \& Mueller, C. (1992). Detection of transcripts for the receptor for macrophage colony-stimulating factor, $c$ fms, in murine osteoclasts. Proceedings of the National Academy of Sciences, 89(20), 96379641.

Takeshita, S., Kaji, K., \& Kudo, A. (2000). Identification and characterization of the new osteoclast progenitor with macrophage phenotypes being able to differentiate into mature osteoclasts. Journal of Bone and Mineral Research, 15(8), 1477-1488.

Yavropoulou, M. P., \& Yovos, J. G. (2008). Osteoclastogenesis--current knowledge and future perspectives. J Musculoskelet Neuronal Interact, 8(3), 204-216. 